九州大学学術情報リポジトリ

Kyushu University Institutional Repository

\title{
Microstructural characteristics of tungsten- base nanocomposites produced from micropowders by high-pressure torsion
}

\section{Edalati, Kaveh}

Department of Materials Science and Engineering, Faculty of Engineering, Kyushu University I WPI, International Institute for Carbon-Neutral Energy Research (WPI-I^2CNER), Kyushu University

Toh, Shoichi

Research Laboratory for High Voltage Electron Microscopy, Kyushu University

Iwaoka, Hideaki

Department of Materials Science and Engineering, Faculty of Engineering, Kyushu University

Horita, Zenj i

WPI, International Institute for Carbon-Neutral Energy Research (WPI-I^2CNER), Kyushu University | Department of Materials Science and Engineering, Faculty of Engineering, Kyushu University

http://hdl. hand le. net/2324/26384

出版情報：Acta Materialia. 60 (9)，pp.3885-3893，2012-05. Elsevier バージョン：

権利関係 : (C) 2012 Acta Materialia Inc. 


\title{
Microstructural characteristics of tungsten-base nanocomposites produced from micropowders by high-pressure torsion
}

\author{
Kaveh Edalati ${ }^{a, b, *}$ Shoichi Toh ${ }^{c}$, Hideaki Iwaoka ${ }^{a}$, Zenji Horita ${ }^{a, b}$ \\ a epartment of Materials Science and Engineering, Faculty of Engineering, Kyushu University, \\ Fukuoka 819-0395, Japan \\ ${ }^{\mathrm{b}}$ WPI, International Institute for Carbon-Neutral Energy Research (WPI-I2CNER), Kyushu \\ University, Fukuoka 819-0395, Japan \\ c Research Laboratory for High Voltage Electron Microscopy, Kyushu University, Fukuoka \\ 819-0395, Japan
}

\begin{abstract}
Micropowder mixtures of $\mathrm{W}-50 \% \mathrm{Al}, \mathrm{W}-50 \% \mathrm{Ti}$ and $\mathrm{W}-50 \% \mathrm{Ni}$ were subjected to severe plastic deformation at $573 \mathrm{~K}$ using high-pressure torsion (HPT). The powder mixtures were consolidated and nanocomposites of W/Ti, W/Ti and W/Ni, with average grain sizes as small as 9, 15 and 12 $\mathrm{nm}$, respectively, were formed by imposing large shear strains. The nanocomposites exhibited Vickers microhardness as high as $\sim 900 \mathrm{Hv}$, a level that has rarely been reported for metal-matrix composites. X-ray diffraction analyses together with high-resolution transmission electron microscopy showed that in addition to grain refinement, an increase in the fraction of grain boundaries up to $20 \%$, the dissolution of elements in each other up to $15 \mathrm{~mol} . \%$, an increase in the lattice strain up to $0.6 \%$, and an increase in density of edge dislocations up to $10^{16} \mathrm{~m}^{-2}$ occurred by HPT. The current study introduces the HPT process as an effective route for the production of ultrahigh-strength W-base nanocomposites, fabrication of which is not generally easy when processing at high temperatures because of interfacial reaction and formation of brittle intermetallics.
\end{abstract}

Keywords: Ultrafine grain; Nanostructure; Severe plastic deformation; Consolidation; Dislocation

\footnotetext{
* Corresponding author at: Department of Materials Science and Engineering, Faculty of Engineering, Kyushu University, Fukuoka 819-0395, Japan. Tel./fax: +81 928022992. E-mail address: Kaveh.edalati@zaiko6.zaiko.kyushu-u.ac.jp (K. Edalati).
} 


\section{Introduction}

Metal-matrix composites have been the subject of scientific investigation for a few decades for high performance structural applications [1]. Among metal-matrix composites, W-base composites with metal reinforcements are of particular interest because of their multifunctionality and ability to have a combination of both ultrahigh strength and good ductility [2,3]. A general problem with the $\mathrm{W}$-base composites with metal reinforcements such as $\mathrm{Al}$ and $\mathrm{Ni}$ is the difficulty in producing a strong interface without suffering chemical reactions or elemental dissolution between matrix and reinforcement [4,5]. These composites are usually fabricated from powder mixtures by solid-state processes such as hot-press sintering or by liquid-phase sintering [2]. The high sintering temperature and long sintering time, which must be used during the production processes, lead to interfacial dissolution and reaction of $\mathrm{W}$ and $\mathrm{Al}$ or $\mathrm{W}$ and $\mathrm{Ni}$ and result in producing brittle intermetallics [4,5]. To avoid the high-temperature sintering problems, consolidation using the high-pressure torsion (HPT) method at low temperatures might be an effective solution.

The HPT method, in which a disc is subjected to intense torsional straining under high pressure, is usually used as a severe plastic deformation method to produce ultrafine-grained materials [6,7]. Following the HPT, the grain size is reduced and the final grain size usually reaches the submicrometer level (> $100 \mathrm{~nm})$ in metallic materials [8-11]. Although semi-metals [12], intermetallics [13], ceramics [14] and few metallic materials [15-18] exhibit grain sizes less than $100 \mathrm{~nm}$ after processing with HPT, achieving the nanograins especially at the level of $10 \mathrm{~nm}$ is still a challenging task.

In addition to grain refinement, the HPT is also useful as a processing tool for consolidation of metallic powders [19,20], ceramic powders [21], metallic machining chips [22,23] and amorphous machining chips [24] without sintering process. The application also includes the consolidation of composite powders such as $\mathrm{Al}-\mathrm{Al}_{2} \mathrm{O}_{3}$ [25-27], Al-SiC [25], Al-C [28,29], Al-Ni [30], $\mathrm{Cu}-\mathrm{Al}_{2} \mathrm{O}_{3}$ [31], $\mathrm{Cu}-\mathrm{NbC}$ [32], $\mathrm{Cu}_{-} \mathrm{SiO}_{2}$ [25,26], $\mathrm{Cu}-\mathrm{C}$ [33,34], $\mathrm{Cu}-\mathrm{Cr}$ [35], $\mathrm{Ti}^{-\mathrm{TiO}}{ }_{2}$ [36], $\mathrm{Ti}-\mathrm{Al}_{2} \mathrm{O}_{3}$ [37,38], Ni-NiO [39], $\mathrm{Ni}-\mathrm{Al}_{3} \mathrm{Ni}_{2}$ [30], $\mathrm{Co}-\mathrm{NiO}$ [40] and $\mathrm{Co}-\mathrm{Al}_{2} \mathrm{O}_{3}$ [41].

In this study, three W-base composite powders, W- 50 mol.\% Al, W- 50 mol.\% Ti and W$50 \mathrm{~mol}$ \% $\mathrm{Ni}$, are subjected to HPT for two main objectives: one is to consolidate the composites at low temperatures without the formation of brittle intermetallics and the other is to produce composites with nanostructures and ultrahigh strength. The $\mathrm{W}-\mathrm{Al}$ and $\mathrm{W}-\mathrm{Ni}$ systems were chosen because they can produce several intermetallics such as $\mathrm{Al}_{12} \mathrm{~W}, \mathrm{Al}_{5} \mathrm{~W}, \mathrm{Al}_{4} \mathrm{~W}, \mathrm{Ni}_{4} \mathrm{~W}, \mathrm{NiW}$ and $\mathrm{NiW}_{2}$, and the W-Ti system was selected as a reference system because it has no formation of intermetallics [42]. The evolution of microstructures during HPT is investigated by microhardness measurements, quantitative X-ray diffraction (XRD) analysis and transmission electron microscopy (TEM).

\section{Experimental Materials and Methods}

W powders with the purity level of 99.99\% were mixed with 50 mol.\% of either $\mathrm{Al}$ powders with the purity level of $99.99 \%$, Ti powders with the purity level of $99.9 \%$ or Ni powders with the 
purity level of $99.99 \%$ by mechanical agitation. The morphology of $\mathrm{Al}, \mathrm{Ti}, \mathrm{Ni}$ and $\mathrm{W}$ powders, having average particle sizes less than $75 \mu \mathrm{m}, 150 \mu \mathrm{m}, 150 \mu \mathrm{m}$ and $3 \mu \mathrm{m}$, respectively, is shown in Fig. 1. HPT was conducted at $573 \mathrm{~K}$ to consolidate the powder mixtures to discs with $10 \mathrm{~mm}$ diameter and $0.8 \mathrm{~mm}$ thickness under a pressure of $P=6 \mathrm{GPa}$. Shear strain, $\gamma(\gamma=2 \pi \mathrm{r} / \mathrm{h}, r$ : distance from disc center, $N$ : number of turns, $h$ : disc thickness), was introduced through rotations for either $N=10$ or 40 turns with a rotation speed of $\omega=1.0 \mathrm{rpm}$.

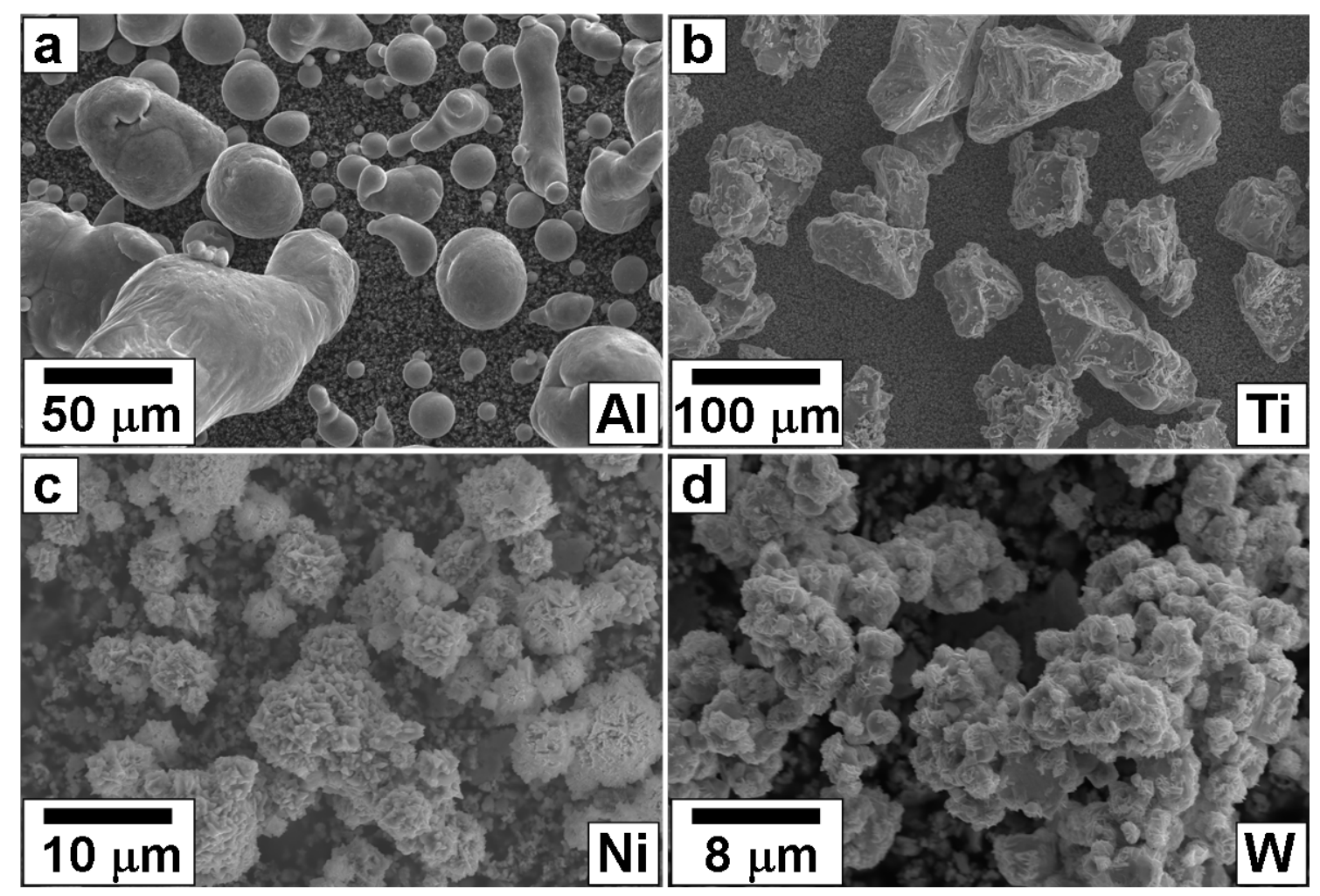

Figure 1. Morphology of (a) Al, (b) Ti, (c) Ni and (c) W powders observed using scanning electron microscopy.

For evaluations, disc samples were first polished to a mirror-like surface on both sides and the sample density was determined by Archimedes' principle using an electronic balance with an accuracy of $0.1 \mathrm{mg}$. Second, the Vickers microhardness was measured on the upper surfaces of discs at every $0.5 \mathrm{~mm}$ from the center with an applied load of $500 \mathrm{~g}$ for $15 \mathrm{~s}$ at 4 different radial directions. Third, XRD analysis was performed on samples using the $\mathrm{Cu} \mathrm{K} \alpha$ radiation at $40 \mathrm{kV}$ and $40 \mathrm{~mA}$ in a scanning step of $0.01^{\circ}$ and a scanning speed of $1 \% \mathrm{~min}$. $\mathrm{LaB}_{6}$ standard powders were used concurrently with the samples during XRD analysis for two reasons: one is to correct the offset of the detector of the XRD analyzer and find the exact peaks positions of the samples, and the other is to correct the inherent peak broadening of the radiation of the XRD analyzer and find the real peak broadening corresponding to lattice strain in the samples. Fourth, for TEM, thin foils were prepared from the disc samples processed for 40 turns at $4 \mathrm{~mm}$ away from the disc center with a focused ion beam (FIB) system. TEM was performed at $300 \mathrm{kV}$ for microstructural observation and for recording selected-area electron diffraction (SAED) patterns. 


\section{Results and Discussion}

Figure 2 shows a histogram of the density levels for the W- 50\% Al, W- 50\% Ti and W$50 \%$ Ni composites consolidated with HPT for 10 and 40 turns. Figure 2 includes the theoretical densities calculated from the densities of $\mathrm{Al}\left(2.79 \mathrm{~g} / \mathrm{cm}^{3}\right)$, Ti $\left(4.51 \mathrm{~g} / \mathrm{cm}^{3}\right)$, Ni $\left(8.90 \mathrm{~g} / \mathrm{cm}^{3}\right)$ and W $\left(19.30 \mathrm{~g} / \mathrm{cm}^{3}\right)$ using the rule of mixtures. The measured density increases with an increase in the numbers of turns from 10 to 40 . However, the values after 40 turns are still lower than those calculated from the rule of mixtures. The relative densities are then almost $\sim 90 \%$ for the three selected composites. The consolidation should be improved if the operating temperature for HPT is increased (for instance to $773 \mathrm{~K}$ ) as reported by Wei et al. [43] in pure W. However, there can be a change in the crystallographic structure or a dissolution of the elements in each other during HPT operation so that the rule of mixtures becomes no longer valid. As will be discussed later, the formation of nanograins may also be responsible for the deviation from the rule of mixtures.

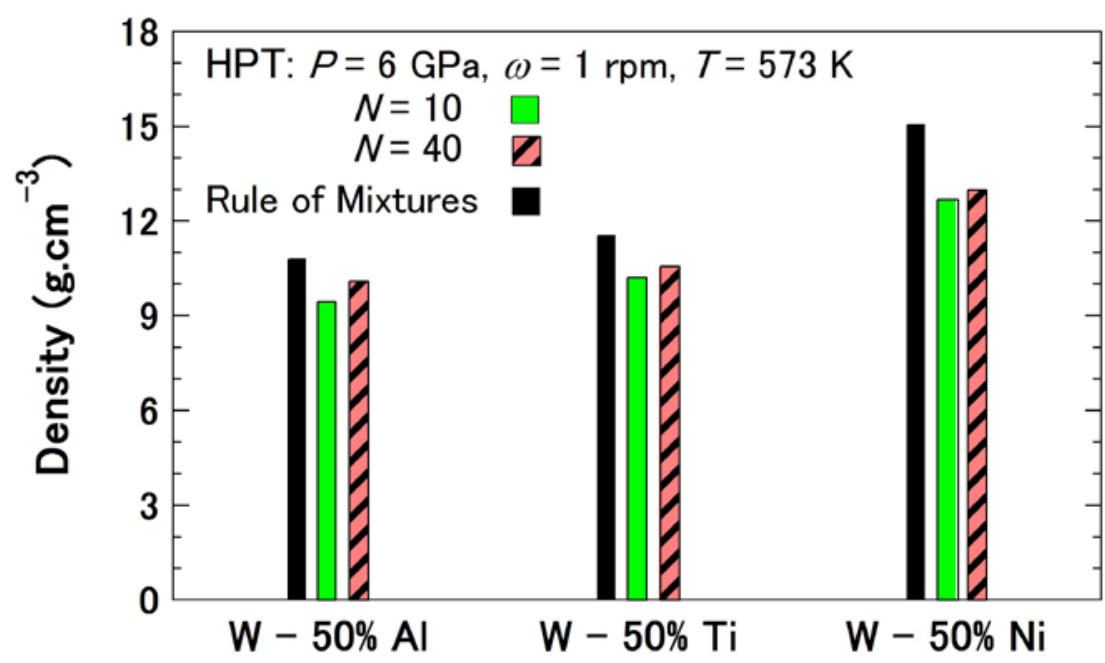

Figure 2. Variations of density for $\mathrm{W}-50 \% \mathrm{Al}, \mathrm{W}-50 \% \mathrm{Ti}$ and $\mathrm{W}-50 \% \mathrm{Ni}$ composites processed with HPT for $N=10$ and $N=40$. Density levels calculated using rule of mixtures are also included.

Figure 3 shows the hardness variation with the distance from the disc center-after (a) 10 turns and (b) 40 turns for the W- 50\% Al, W- 50\% Ti and W- 50\% Ni composites. The microhardness increases with an increasing number of turns and an increasing distance from the disc center. The saturation of the hardness level appears in the disc samples after 40 turns and at 2 $\mathrm{mm}$ away from the disc center. The difference in the hardness behavior arises because the magnitude of strain created through HPT increases with increasing the turn and the distance from the disc center. The hardness level at the saturation exceeds $800 \mathrm{Hv}$ for all composites and even reaches as high as $\sim 920 \mathrm{Hv}$ for the $\mathrm{W}$ - $50 \% \mathrm{Al}$ composite. It is noted that such hardness levels are higher than those of HPT-processed metals and alloys reported thus far [6-12] and are well comparable to those of HPT-processed pure W $[43,44]$ and intermetallic-based nanocomposites [30]. 

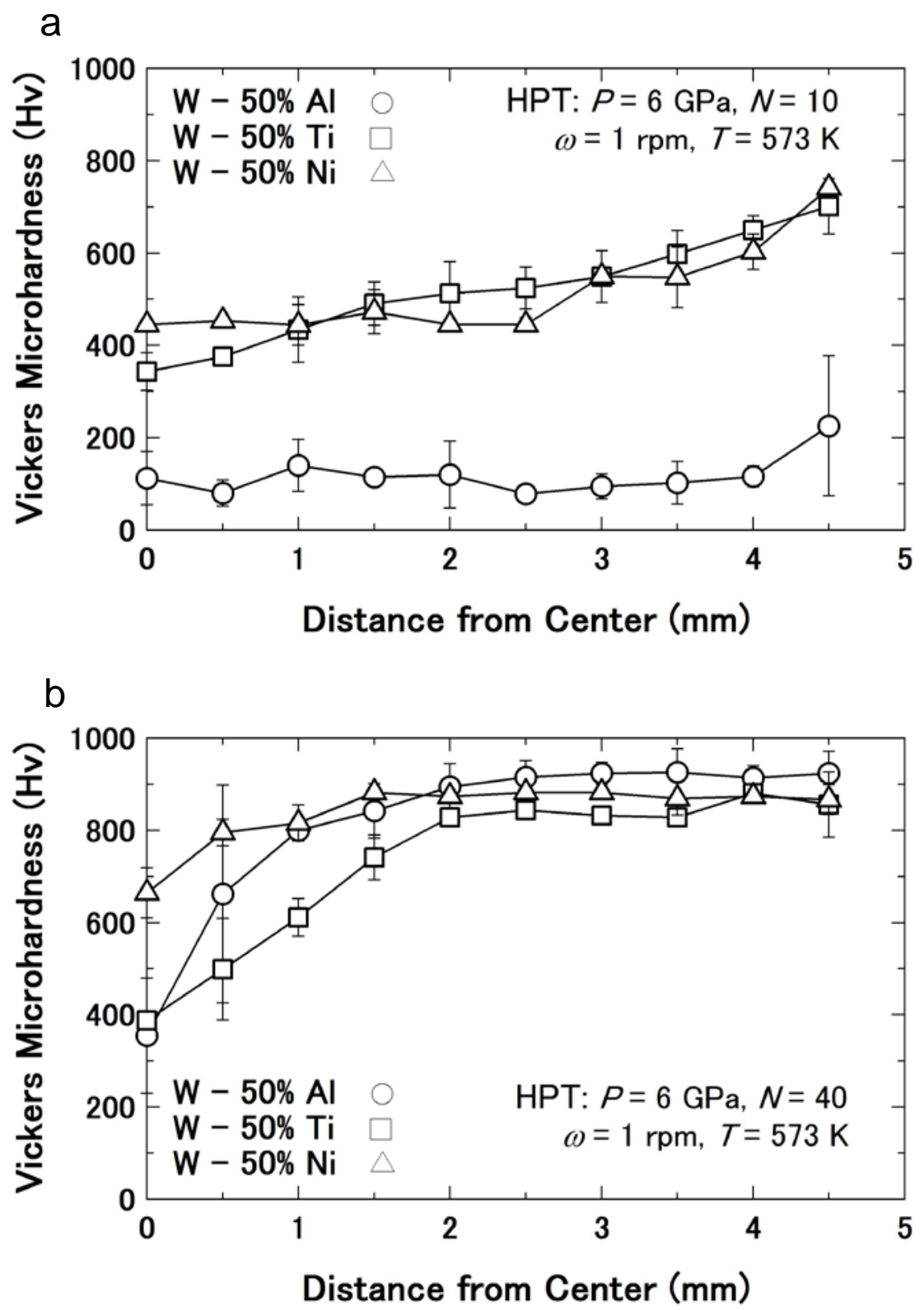

Figure 3. Variations of Vickers microhardness plotted along distance from disc center for W- $50 \%$ Al, W- 50\% Ti and W- 50\% Ni composites after processing with HPT for (a) $N=10$ and (b) $N=40$.

XRD profiles of (a) W- 50\% Al, (b) W- 50\% Ti and (c) W- 50\% Ni are shown in Fig. 4 for the powder mixtures and for the discs consolidated by HPT for 10 and 40 turns. The peaks for the standard $\mathrm{LaB}_{6}$ powders are also seen in the XRD profiles. An examination of Fig. 4 indicates the four important points.

(i) No intermetallic phase is detected after processing of powders with HPT within the sensitivity limit of the present XRD analysis. The results are consistent with the equilibrium phase diagram of the $\mathrm{W}-\mathrm{Ti}$ system which predicts the presence of the $\mathrm{W}$ and $\mathrm{Ti}$ phases at room temperature, but are contrary to the phase diagrams of the $\mathrm{W}-\mathrm{Al}$ and $\mathrm{W}-\mathrm{Ni}$ systems which predict the formation of $\mathrm{Al}_{4} \mathrm{~W}+\mathrm{W}$ phases for the W/Al composite [42] and the NiW intermetallics for the W/Ni composite [42]. 

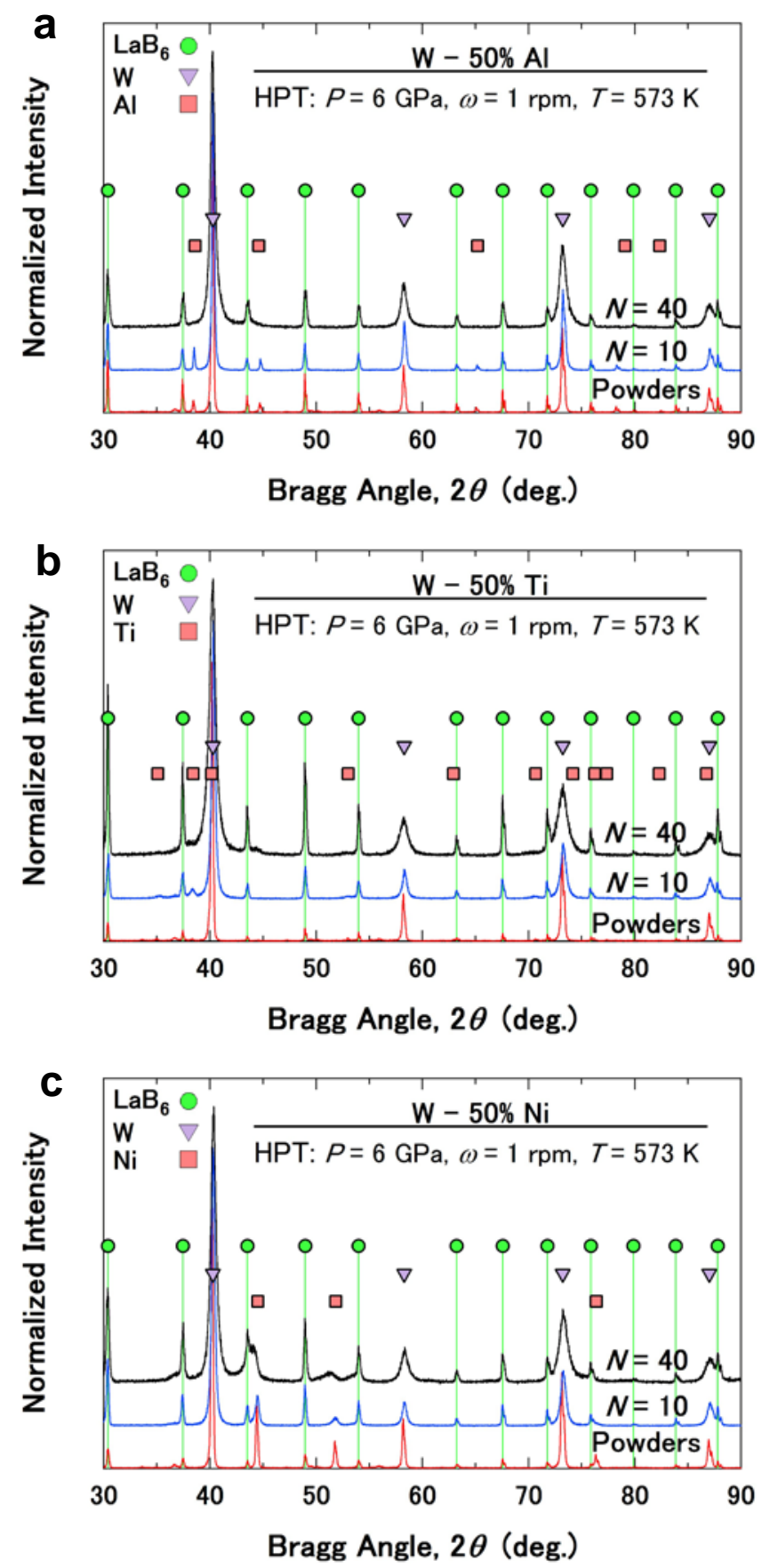

Figure 4. XRD profiles of (a) W- 50\% Al, (b) W- 50\% Ti and (c) W- 50\% Ni composites processed by HPT for $N=10$ and $N=40$ including as-received powder mixtures.

(ii) The peaks of $\mathrm{Al}$ and $\mathrm{Ti}$ disappear for the samples subjected to HPT for 40 turns. This suggests that the $\mathrm{Al}$ and $\mathrm{Ti}$ powders may be dissolved in the $\mathrm{W}$ phase but, as will be discussed below using the SAED patterns, it turns out that both $\mathrm{Al}$ and $\mathrm{Ti}$ are present in the microstructures after 40 turns. The reasons for the disappearance of $\mathrm{Al}$ and Ti peaks in the XRD profiles may be considered as follows: First, the atomic scattering factor which is used to describe the intensity of diffraction is higher for $\mathrm{W}$ when compared to that for $\mathrm{Al}$, $\mathrm{Ti}$ and $\mathrm{Ni}$ because the atomic number of $\mathrm{W}$ (74) is much higher than $\mathrm{Al}$ (13), $\mathrm{Ti}$ (22) and $\mathrm{Ni} \mathrm{(28)} \mathrm{[44].} \mathrm{Second,} \mathrm{strong} \mathrm{diffraction} \mathrm{from} \mathrm{the} \mathrm{W}$ powders may musk the week peaks of $\mathrm{Al}$ and Ti. Third, diffracted beams from the $\mathrm{Al}$ and $\mathrm{Ti}$ 
powders are absorbed by $\mathrm{W}$ in the well-mixed composites.

(iii) The full width at half maximum (FWHM) increases significantly with torsional straining using HPT. The peak broadening is an important evidence proving the occurrence of lattice strains, dislocations generation and grain fragmentation during the HPT processing. Here, the lattice strain and the dislocation density were calculated from the FWHM values using the Williamson-Hall method [45] after removing the effect of the $\mathrm{K} \alpha_{2}$ radiation and after subtracting the inherent peak broadening of the radiation of the XRD analyzer. Since the peak intensities for $\mathrm{Al}$, $\mathrm{Ti}$ and Ni were not high enough, the values were estimated only for the $\mathrm{W}$ phase. The lattice strain $\varepsilon$, and the dislocation density $\rho$ ( $\rho=14.4 \varepsilon^{2} / b^{2}, b$ : burgers vector), are plotted against the number of turns in Figs. 5 (a) and (b), respectively. The lattice strain and the dislocation density increase with the torsional straining and reach the levels as high as $\varepsilon=0.3-0.6 \%$ and $\rho=10^{15}-10^{16} \mathrm{~m}^{-2}$ after 40 turns. Although the XRD analyses suggest that the dislocation density is so high in these composites, detailed microstructural analysis, as will be given below, clearly confirms the presence of the dislocations within the nanograins.

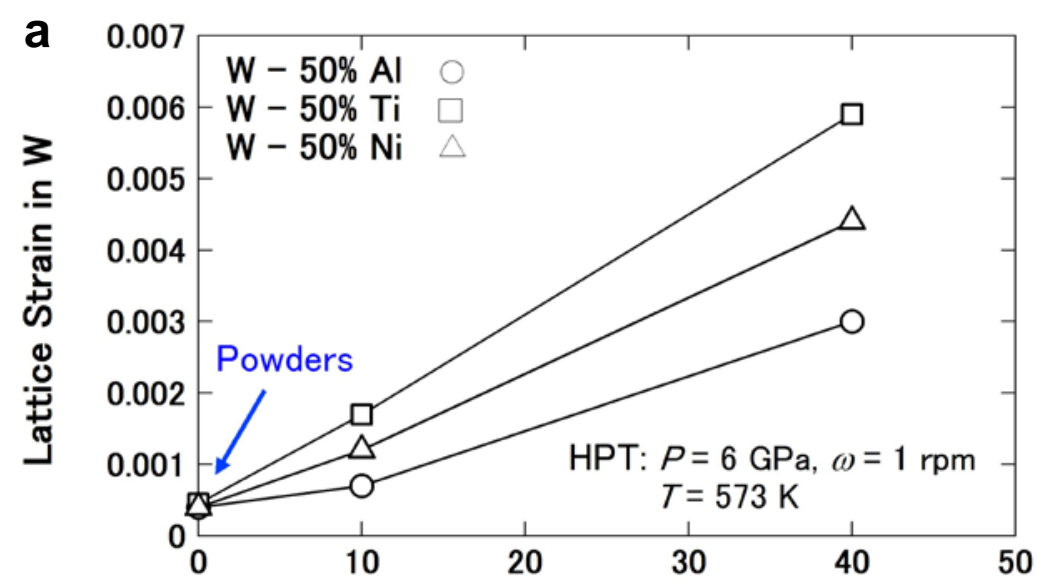

Number of Turns, $\boldsymbol{N}$

b

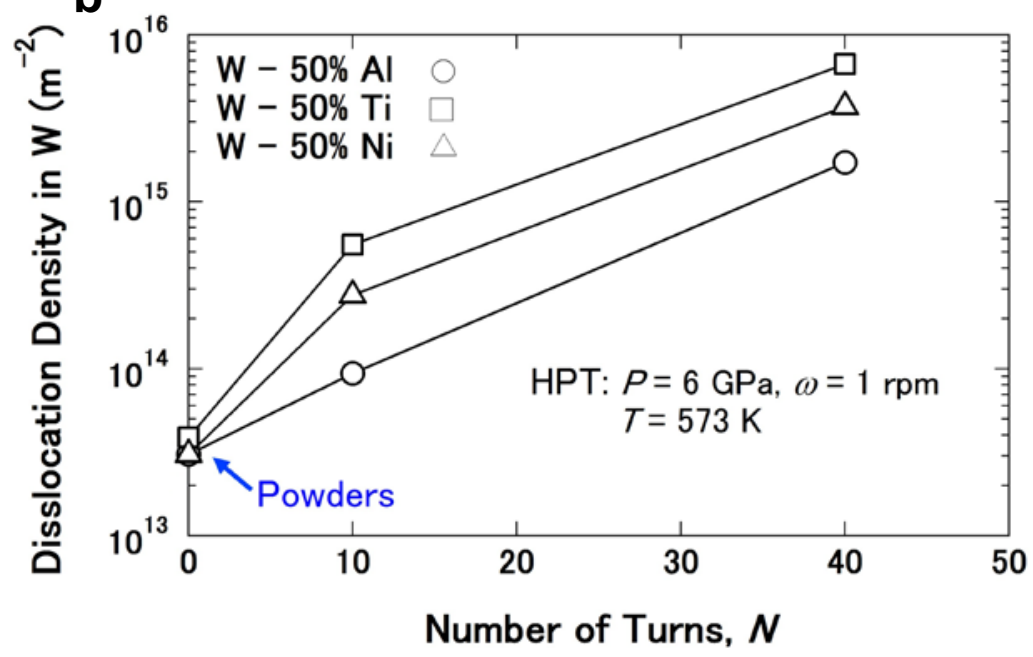

Figure 5. Variations of (a) lattice strain and (b) dislocation density in $\mathrm{W}$ grains as a function of numbers of turns for $\mathrm{W}-50 \% \mathrm{Al}, \mathrm{W}-50 \% \mathrm{Ti}$ and $\mathrm{W}-50 \% \mathrm{Ni}$ composites processed by HPT including as-received powder mixtures. The values were calculated from the XRD profiles using the Williamson-Hall method. 
(iv) A close examination of the XRD profiles indicates that some peak positions are shifted to some extent to lower or higher angles in the HPT-processed samples with respect to the peak positions before HPT. It is evident that the lattice parameters must be changed during the HPT processing. Although the high lattice strain or large fraction of grain boundaries may influence the lattice parameters in these materials, the lattice parameters may also change because of dissolution of elements in each other. Here, the lattice parameter $(a)$ of each element was determined with the Nelson-Riley extrapolation method [45] and the amount of $\mathrm{Al}, \mathrm{Ti}$ and $\mathrm{Ni}$ dissolved in $\mathrm{W}$ and the amount of $\mathrm{W}$ dissolved in $\mathrm{Al}, \mathrm{Ti}$ and $\mathrm{Ni}$ were calculated using the Vegard's law [45]. It should be noted that, since the crystal structures of the selected elements are different (Al and Ni: fcc, Ti: hcp, W: bcc), the lattice parameters cannot be used directly in the Vegard's law for the calculation of the elemental dissolution. Instead, the atomic distances $(R)$ were calculated from the lattice parameters ( $R=\sqrt{3} a / 4$ for bcc, $R=\sqrt{2} a / 4$ for fcc, $R=a / 2$ for hcp) and the values of $R$ were used in the Veagrd's law. For example, the mole fraction of $\mathrm{Al}$ in $\mathrm{W}$ was calculated as $X_{A l}=\left(R_{W}-R_{W 0}\right) /\left(R_{A l 0}-R_{W 0}\right)$, where $R_{W}$ is the atomic distance for W calculated from the XRD analysis, and $R_{W O}=0.137 \mathrm{~nm}$ and $R_{A l 0}=0.143 \mathrm{~nm}$ are the atomic distances for the standard samples of pure $\mathrm{W}$ and $\mathrm{Al}$. Figures 6 plots the amounts of $\mathrm{Al}$, Ti and Ni dissolved in $\mathrm{W}$ and the amount of $\mathrm{W}$ dissolved in $\mathrm{Al}, \mathrm{Ti}$ and $\mathrm{Ni}$ as a function of the number of turns. Since the peaks of $\mathrm{Al}$ and $\mathrm{Ti}$ can not be detected in the XRD profiles after HPT for 40 turns, the corresponding data points are not shown in Fig. 6. It is apparent from Fig. 6 that the amount of elemental dissolution increases with increasing the number of turns.

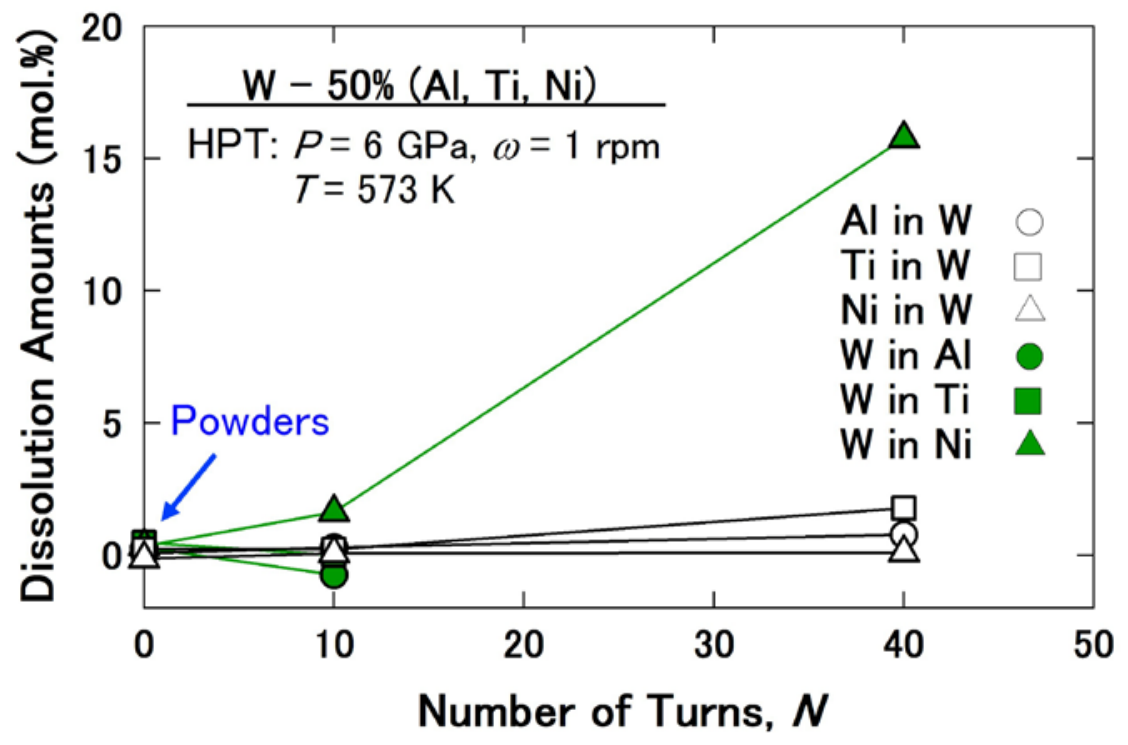

Figure 6. Variations of $\mathrm{Al}, \mathrm{Ti}$ and $\mathrm{Ni}$ amounts dissolved in $\mathrm{W}$ and $\mathrm{W}$ amounts dissolved in $\mathrm{Al}$, Ti and $\mathrm{Ni}$ as a function of numbers of turns for $\mathrm{W}-50 \% \mathrm{Al}, \mathrm{W}-50 \% \mathrm{Ti}$ and $\mathrm{W}-50 \% \mathrm{Ni}$ composites processed by HPT including as-received powder mixtures. The values were calculated from lattice parameter and atomic distance measurements using the Vegard's law and the lattice parameters were calculated from the XRD profiles using the Nelson-Riley extrapolation Method. 
An inspection of the equilibrium phase diagrams for the $\mathrm{W}-\mathrm{Al}, \mathrm{W}-\mathrm{Ti}$ and $\mathrm{W}-\mathrm{Ni}$ systems at room temperature show that the solubility of $\mathrm{Al}$ in $\mathrm{W}$ is $\sim 2 \mathrm{~mol} \%$, the solubility of $\mathrm{Ti}$ in $\mathrm{W}$ is $\sim 10$ mol.\%, the solubility of $\mathrm{W}$ in $\mathrm{Ni}$ is $\sim 10$ mol.\% and the solubility of $\mathrm{W}$ in $\mathrm{Al}, \mathrm{W}$ in $\mathrm{Ti}$ and $\mathrm{Ni}$ in $\mathrm{W}$ are negligible at room temperature [42]. Therefore, except for the amount of $\mathrm{W}$ in $\mathrm{Ni}, ~ 15 \mathrm{~mol} . \%$, which is in a supersaturated condition after HPT for 40 turns, the dissolution of other elements in each other is less than the predictions of the equilibrium phase diagrams.

TEM bright-field (BF) images, dark-field (DF) images and corresponding SAED patterns are shown in Fig. 7 for (a) W- 50\% Al, (b) W- 50\% Ti and (c) W- 50\% Ni composites after processing by HPT for 40 turns. Note that the three micrographs correspond to the steady state where the hardness remains unchanged with straining. TEM characterization indicates several important points.
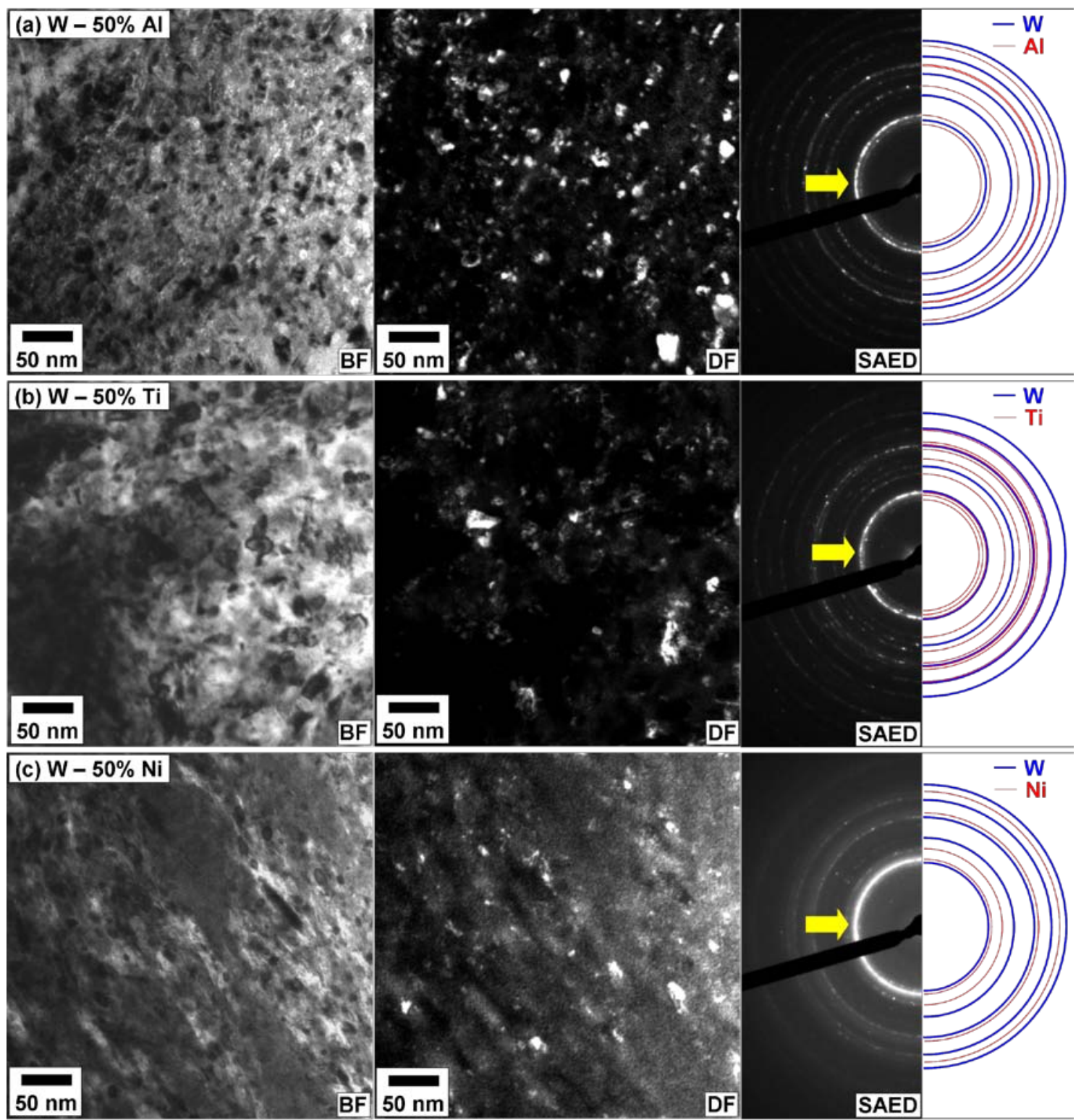

Figure 7. TEM bright-field images (left), dark-field images (center) and corresponding SAED patterns (right) for (a) W- 50\% Al, (b) W- 50\% Ti and (c) W- 50\% Ni composites processed by HPT for $N=40$. Dark-field images taken with diffracted beams indicated by arrows in SAED patterns which correspond to both $\mathrm{W}$ phase and $\mathrm{Al}$, Ti and Ni phases. 
(i) The diffracted beams for $\mathrm{Al}$ and $\mathrm{Ti}$ which was not detected in the XRD patterns are clearly visible in the SAED patterns. This is contrary to the equilibrium phase diagrams and will be discussed later.

(ii) The SAED patterns show that no intermetallic forms by HPT and this is consistent with the XRD analyses.

(iii) DF images indicate that the microstructures consist of nanograins after HPT. Note that the DF images were taken with the diffracted beams indicated by the arrows in the SAED patterns, which include both phases. The grain size distribution at the steady state obtained from the dark-field images for $\sim 50$ grains is shown in Fig. 8. The average grain size is as small as $\sim 9 \mathrm{~nm}$, $\sim 15 \mathrm{~nm}$ and $\sim 12 \mathrm{~nm}$ for $\mathrm{W}-50 \% \mathrm{Al}, \mathrm{W}-50 \% \mathrm{Ti}$ and $\mathrm{W}-50 \% \mathrm{Ni}$, respectively, which are well in the nanometer range. Figure 9 shows two representative high-magnification images taken by HRTEM. It is confirmed that the grains are at the nanometer level in (a) $\mathrm{W}-50 \% \mathrm{Al}$ and (b) $\mathrm{W}-50 \% \mathrm{Ti}$ composites. The grain sizes obtained in this study are much smaller than those obtained in HPT-processed metals and alloys [6-12], but are consistent with the value reported for HPT-processed W- 25\% Cu [15].

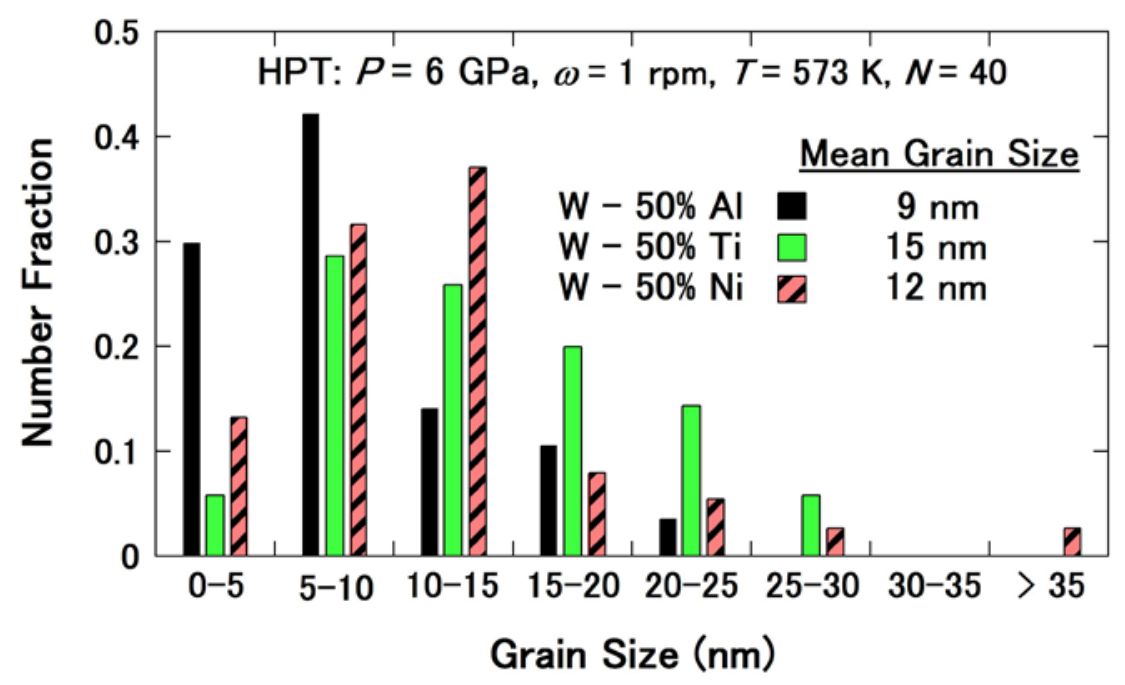

Figure 8. Number fraction of grain size distribution for $\mathrm{W}-50 \% \mathrm{Al}, \mathrm{W}-50 \% \mathrm{Ti}$ and $\mathrm{W}-50 \% \mathrm{Ni}$ composites processed by HPT for $N=40$. The average grain size is $\sim 9 \mathrm{~nm}$ for $\mathrm{W}-50 \% \mathrm{Al}, \sim 15 \mathrm{~nm}$ for $\mathrm{W}-50 \% \mathrm{Ti}$, and $12 \mathrm{~nm}$ for $\mathrm{W}-50 \% \mathrm{Ni}$.

(iv) Ring patterns from the SAED analyses indicate that the most nanograins are separated by high angles of misorientations after HPT processing.

(v) A close examination of the SAED patterns indicates that the positions of some diffracted beams are shifted after HPT with respect to those obtained using the high-purity metals. For precise examination of the shifts, the three SAED patterns in Fig. 7 were scanned using an image processing software in 11 radial directions and the beam intensities at each distance from the center of SAED pattern were recorded. Since the distance from the center of SAED pattern corresponds to the reciprocal spacing, the data points were converted to real spacing and plotted in the form of the normalized intensity against the real spacing (hereafter called d-spacing) in Figs. 10 
for (a) W- 50\% Al, (b) W- 50\% Ti and (c) W- 50\% Ni. The distances between the same atomic planes obtained using the high-purity standard samples are also included in Fig. 10. As shown in Fig. 10, the d-spacings for Ti and $\mathrm{W}$ exhibit negligible change with respect to high purity metals and this is consistent with the XRD analyses. The d-pacing for Ni increases and this is due to dissolution of $\mathrm{W}$ in Ni which agrees with the Vegard's law and the XRD analyses. The d-spacing for Al also changes after HPT processing and it increases from $0.233 \mathrm{~nm}$ to $0.241 \mathrm{~nm}$ for (111) planes, from $0.203 \mathrm{~nm}$ to $0.208 \mathrm{~nm}$ for (200) planes and from $0.143 \mathrm{~nm}$ to $0.148 \mathrm{~nm}$ for (220) planes. If the lattice parameter (a) of $\mathrm{Al}$ in Fig. 10(a) is determined with the Nelson-Riley extrapolation method, it turns out that $a$ for $\mathrm{Al}$ increase from 4.04 A to 4.17 A in this study. Since dissolution of $\mathrm{W}$ in $\mathrm{Al}$ is zero according to the equilibrium $\mathrm{W}-\mathrm{Al}$ phase diagram and any assumed dissolution of $\mathrm{W}$ in $\mathrm{Al}$ must result in decreasing the lattice parameter of Al according to the Vegard's law, this observation is totally inconsistent with the equilibrium phase diagram and violates the vegard's law. Several reasons may be considered for this inconsistency.
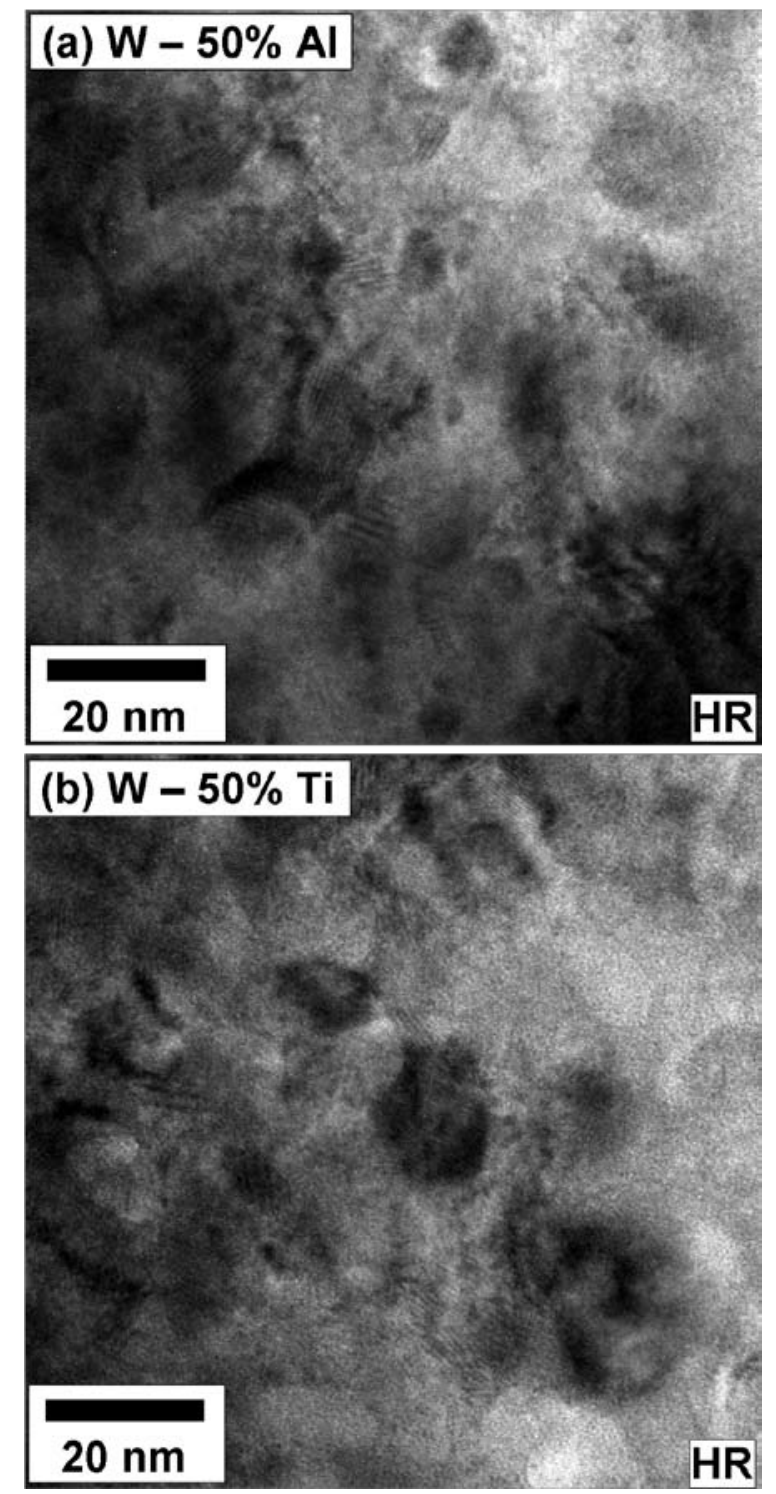

Figure 9. High resolution TEM images for (a) W- 50\% Al and (b) W- 50\% Ti processed by HPT for $N=40$. 

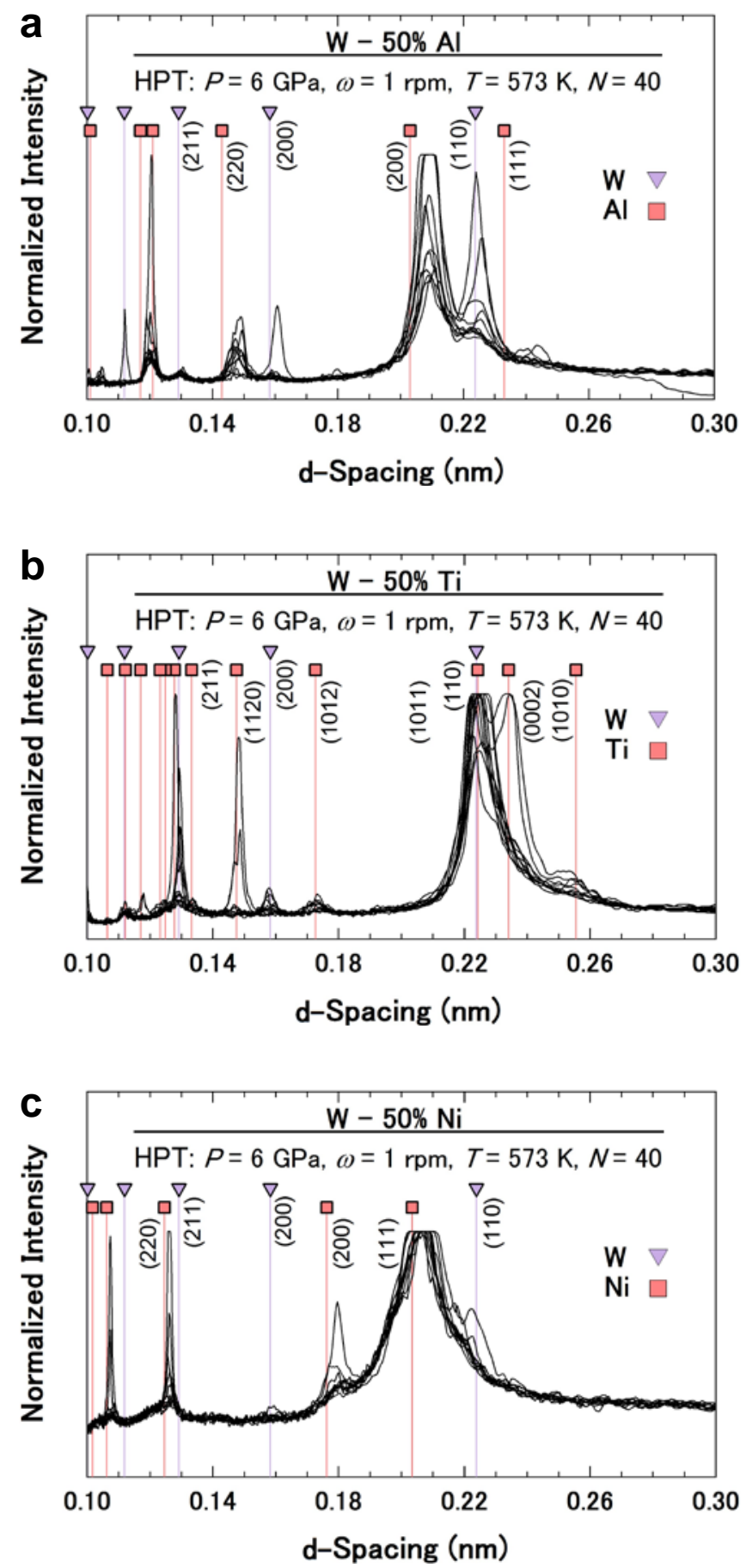

Figure 10. Electron diffraction profiles of (a) W- 50\% Al, (b) W- 50\% Ti and (c) W- 50\% Ni composites processed by HPT for $N=40$ obtained by linear scanning of SAED patterns in 11 radial directions and converting reciprocal of distance from SAED center to spacing. d-spacing values for pure Al, Ti, Ni and W are also included. Compared to pure metals, d-spacings after HPT remained almost unchanged for Ti and W, but they increases after HPT for Al and Ni.

First, the large fraction of highly strained nanograin boundaries, as will be discussed below, may distort the Al lattices and increase the lattice parameters. Second, the dissolution of small amount of $\mathrm{W}$ in $\mathrm{Al}$ may occur in the non-equilibrium condition after HPT processing and lead to 
lattice expansion of Al to violate the Vegard's Law as several other reports where the Vegard's law is not valid for systems such as $\mathrm{Al}-\mathrm{Ni}$ because of the presence of many structural vacancies substututionally formed in the lattice [46], Si-Ge-C because of the elongation of atomic bonds [47] and $\mathrm{Li}_{\mathrm{x}} \mathrm{FePO}_{4}$ because of the strong interaction between the electrons and atoms [48]. Third, a metastable Al/W intermetallic with an Al-like crystal structure and an expanded lattice parameter may form by reaction of a small amount of $\mathrm{W}$ with $\mathrm{Al}$. It should be noted that according to the $\mathrm{W}-\mathrm{Al}$ equilibrium phase diagram, reaction of $\sim 7.7 \mathrm{~mol}$.\% of $\mathrm{W}$ with $\mathrm{Al}$ results in a pronounced lattice expansion $(a=0.758 \mathrm{~nm})$ and formation of stable $\mathrm{Al}_{12} \mathrm{~W}$ intermetallic with bcc crystal structure.

Figure 11 shows lattice images of the HPT-processed W- 50\% Al composite after 40 turns, where (a) is a lattice image of a grain with a corresponding diffractogram obtained by fast Fourier transform (FFT) analysis, (b) is a reconstructed lattice image of (a) obtained by inverse FFT from $\{110\}$ spots in the difractograms, (c) is a lattice image of a grain interior with a corresponding difractograms, and (d) is a reconstructed lattice image of the squared region in (c) obtained by inverse FFT from (110) spots in the difractograms. The FFT difractograms and the d-spacing measurements suggest that the both lattice images correspond to the $\mathrm{W}$ grains.

Examination of Fig. 11(b) shows that no dislocation is detected in this grain using the selected electron beam incidence. In contrast to coarse-grained materials, in which the dislocations pile up is very usual after plastic deformation, the lack of dislocation accumulation within the nanograins is not surprising even after introducing the large shear strains. The high-angle grain boundaries in nanograins act as both dislocation sources and sinks so that dislocation move fast and they disappear in the grain boundaries [49,50]. Fig. 11(b) indicates that the lattice strain is low in the grain interior, but increases along the grain boundary which appears at the edge of the image. Detailed analysis reveals that no local distortion and change in the d-spacing occurs from the grain center to grain boundary. However, as a consequence of straining, the grain is distorted so that the $\mathrm{d}$-spacing becomes higher in the [011] direction than in [110] and [101] directions. If the grain sizes are as small as $9 \mathrm{~nm}$ and the width of the grain boundaries are considered to be in the range of $a / 2$ to $a(a=0.316 \mathrm{~nm}$ is the lattice parameter of $\mathrm{W})$, estimation shows that $10-20$ vol.\% of the microstructure is occupied by highly strained grain boundaries. This confirms that the lattice strain is really high in these nano-composites which is consistent with the XRD analyses described in Fig. 5(a).

Examination of Fig. 11(d) clearly shows that there is an edge dislocation in the interior of the grain. It should be noted that the lattice images of total 25 grains were analyzed in this study and one edge dislocation within one grain was detected for three grains out of the 25 grains. Considering the grain size as small as $9 \mathrm{~nm}$, an estimation of the dislocation density results in $1.9 \times 10^{16} \mathrm{~m}^{-2}$, provided that a single dislocation exists in $12 \%$ of nanograins (3 out of 25 ). It turns out that such an unusual dislocation density within the nanograins is comparable or even higher than that estimated by XRD analyses. It should be noted that the exact dislocation density cannot be measured by any of XRD analysis and TEM examination because of several reasons. First, estimation of dislocation density using XRD analysis depends on the applied model (Williamson-Hall method in this study), but none of the models developed up to date is capable of 
estimating the exact dislocation density within the grains. Second, TEM examines the dislocations within the limited number of grains (25 grains in this study), and thus, it estimates the localized dislocation density. Statistically, much more grains should be examined using TEM to calculate the dislocation density, but it is technically difficult to examine the lattice images of many grains in these $\mathrm{W}$-base composites by TEM because of the high atomic number of $\mathrm{W}$. Third, only the edge dislocations with Burgers vector perpendicular to the incident electron beam are visible in TEM lattice images. Fourth, although screw dislocations with three-fold cores are mainly generated in $\mathrm{W}$ during plastic deformation [51,52], they can not be detected easily in the lattice images using TEM even if they are present. Therefore, TEM underestimates the localized dislocation density within the nanograins.

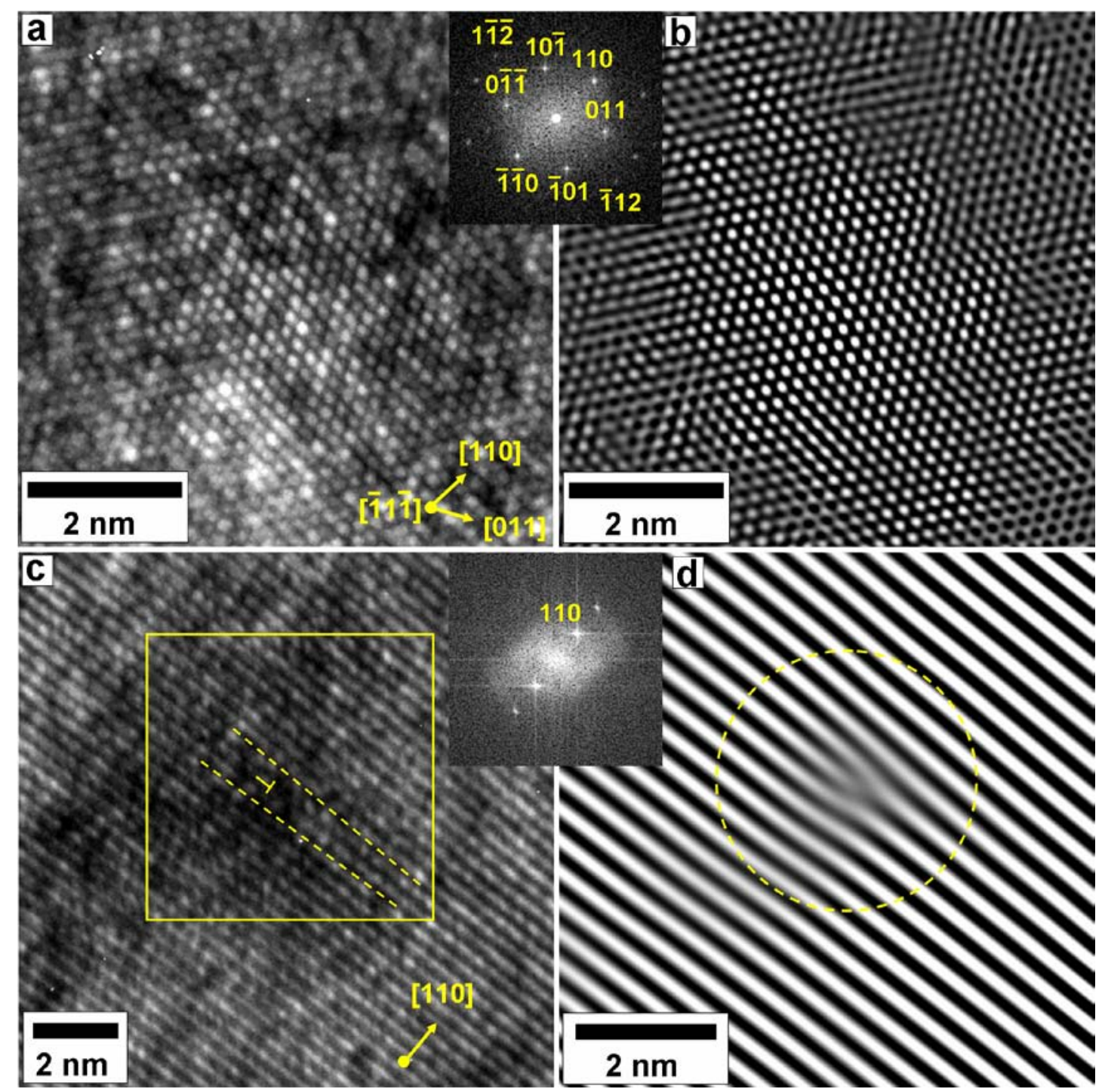

Figure 11. TEM lattice images for $\mathrm{W}-50 \% \mathrm{Al}$ processed by HPT for $N=40$. (a) and (c) TEM lattice images and corresponding FFT diffractograms corresponding to W, and (b) and (d) reconstructed lattice images of (a) and square region of (c), respectively, processed by inverse FFT from \{110\} beams of FFT diffractograms. Reconstructed lattice image in (b) shows low lattice strain in grain interior and high lattice strain along grain boundary. T mark in (c) represents an edge dislocation within a nanograin and dotted circle in (d) shows a region distorted by dislocation core. 


\section{Conclusions}

(1) Nanograined W-base composites, W/Al, W/Ti and W/Ni, were produced from the elemental micropowder mixtures using HPT processing at $573 \mathrm{~K}$.

(2) The density and hardness measurements suggested that ultrahigh strength composites with an appreciable consolidation level were produced by introducing intense strain under a high pressure through HPT processing.

(3) The ultrahigh hardness values in these composites, 900 HV, resulted from the formation of nanograins with the size of $\sim 10 \mathrm{~nm}$, large fraction of highly strained grain boundaries with high missorientation angles and large fraction of dislocation density within the nanograins.

(4) Lattice parameter measurements showed that except for the amount of $\mathrm{W}$ dissolved in $\mathrm{Ni}$ which was 15 mol.\%, the dissolution of other elements in each other was less than 2 mol.\% and the dissolution of $\mathrm{W}$ in $\mathrm{Al}$ could not be estimated because it violated the Vegard's law.

(4) The present procedure using HPT processing contrasts with conventional hot sintering processes where the high sintering temperature results in interfacial reaction and formation of brittle intermetallics.

\section{Acknowledgements}

One of the authors (KE) thanks the Japan Society for Promotion of Science (JSPS) for a postdoctoral scholarship. This work was supported in part by a Grant-in-Aid for Scientific Research from the MEXT, Japan, in Innovative Areas "Bulk Nanostructured Metals" and in part by Kyushu University Interdisciplinary Programs in Education and Projects in Research Development (P\&P).

\section{References}

[1] Matthews FL, Rawlings RD. Composite Materials, Engineering and Science, Cambridge: Woodhead Publishing Limited; 2003.

[2] Kim JC, Ryu SS, Kim YD, Moon IH. Scripta Mater 1998;39:669.

[3] Garmong G, Williams JC. Metall Trans A 1975;6:1711.

[4] Sharma SC, Narayanan PR, Sinha PP, Nagarajan KV. J Mater Sci 1994;29:5719.

[5] Metcalfe MC. Composite Materials, Vol. 1, Interface in Metal Matrix Composites, New York: Academic Press; 1974.

[6] Valiev RZ, Estrin Y, Horita Z, Langdon TG, Zehetbauer MJ, Zhu YT. JOM 2006;58(4):33.

[7] Zhilyaev AP, Langdon TG. Prog Mater Sci 2008;53:893.

[8] Zehetbauer M, Grossinger R, Krenn H, Krystian M, Pippan R, Rogl P, Waitz T, Wurschum R. Adv Eng Mater 2010;12:692.

[9] Kawasaki M, Alhajeri SN, Xu C, Langdon TG, Mater Sci Eng A 2011;529:345.

[10] Figueiredo RB, Cetlin PR, Langdon TG. Mater Sci Eng A 2011;528:8198.

[11] Wongsa-Ngam J, Kawasaki M, Zhao Y, Langdon TG. Mater Sci Eng A 2011;528:7715.

[12] Valiev RZ, Islamgaliev RK, Alexandrov IV. Prog Mater Sci 2000;45:103.

[13] Rentenberger C, Waitz T, Karnthaler HP. Mater Sci Eng A 2007;462:283.

[14] Edalati K, Toh S, Ikoma Y, Horita Z. Scripta Mater 2011;65:974.

[15] Sabirov I, Pippan R. Scripta Mater 2005;52:1293.

[16] Zhao YH, Zhu YT, Liao XZ, Horita Z, Langdon TG. Appl Phys Lett 2006;89:121906.

[17] Kuramoto S, Furuta T, Nagasako N, Horita Z. Appl Phys Lett 2009;95:211901.

[18] An XH, Lin QY, Wu SD, Zhang ZF, Figueiredo RB, Gao N, Langdon TG. Scripta Mater 
2011;64:954.

[19] Korznikov AV, Safarov I, Laptionok DV, Valiev RZ. Acta Metall. Mater 1991;39:3193.

[20] Shen H, Guenther B, Koanikov AV, Valiev RZ. Nunostruct Mater 1995;6:385.

[21] Edalati K, Horita Z. Scripta Mater 2010;63:174.

[22] Zhilyaev AP, Gimazov AA, Raab GI, Langdon TG. Mater Sci Eng A 2008;486:123.

[23] Zhilyaev AP, Swaminathan S, Gimazov AA, McNelley TR, Langdon TG. J Mater Sci 2008;43:7451.

[24] Edalati K, Yokoyama Y, Horita Z. Mater Trans 2010;51:23.

[25] Alexandrov IV, Zhu YT, Lowe TC, Islamgaliev RK, Valiev RZ. Nanostruct Mater 1998;10:45.

[26] Alexandrov IV, Zhu YT, Lowe TC, Islamgaliev RK, Valiev RZ. Metall Mater Trans A 1998;29:2253.

[27] Ashida M, Horita Z, Kita T, Kato A. Mater Trans 2012;53:13.

[28] Tokunaga T, Kaneko K, Horita Z. Mater Sci Eng A 2008;490:300.

[29] Tokunaga T, Kaneko K, Sato K, Horita Z. Scripta Mater 2008;58:735.

[30] Edalati K, Toh S, Watanabe M, Horita Z. Scripta Mater 2012; 66:386.

[31] Islamgaliev RK, Buchgraber W, Kolobov YR, Amirkhanov NM, Sergueeva AV, Ivanov KV, Grabovetskaya GP. Mater Sci Eng A 2001;319-321:872.

[32] Long BD, Umemoto M, Todaka Y, Othman R, Zuhailawati. Mater Sci Eng A 2011;528:1750.

[33] Li H, Misra A, Zhu Y, Horita Z, Koch CC, Holesinger TG. Mater Sci Eng A 2009;523:60.

[34] Li H, Misra A, Horita Z, Koch CC, Mara NA, Dickerson PO, Zhu Y. J Appl Phys 2009;95:071907.

[35] Sauvage X, Jessner P, Vurpillot F, Pippan R. Scripta Mater 2008;58:1125.

[36] Stolyarov VV, Zhu YT, Lowe TC, Islamgaliev RK, Valiev RZ. Mater Sci Eng A 2000;282:78.

[37] Edalati K, Iwaoka H, Horita Z, Tanaka M, Higashida K, Fujiwara H, Ameyama K. Kovove Mater 2011;49:85.

[38] Edalati K, Iwaoka H, Horita Z, Konno M, Sato T. Mater Sci Eng A 2011;529:435.

[39] Bachmaier A, Hohenwarter A, Pippan R. Scripta Mater 2009;61:1016.

[40] Menendez E, Sort J, Langlais V, Zhilyaev A, Munoz JS, Surinach S, Nogues J, Baro MD. J Alloys Compd 2007;434-435:505.

[41] Menendez E, Salazar-Alvarez G, Zhilyaev AP, Surinach S, Baro MD, Nogues J, Sort J. Adv Funct Mater 2008;18:3293.

[42] Baker H. ASM Handbook, Vol. 3, Alloy Phase Diagram, Ohio: ASM International; 1992.

[43] Wei Q, Zhang HT, Schuster BE, Ramesh KT, Valiev RZ, Kecskes LJ, Dowding RJ, Magness L, Cho K. Acta Mater 2006;54:4079.

[44] Edalati K, Horita Z. Scripta Mater 2011;64:161.

[45] Cullity BD. Elements of X-ray Diffraction, London: Addison-Wesley Publishing Company Inc.; 1978.

[46] Taylor A. X-ray Metallography, New York: Wiley; 1961.

[47] Kouvetakis J, Nesting D, Smith DJ. Chem Mater 1998;10:2935.

[48] Yamada A, Koizumi H, Nishimura SI, Sonoyama N, Kanno R, Yonemura M, Nakamura T, Kobayashi Y. Nature Mater 2006;5:357.

[49] Meyers MA, Mishra A, Benson DJ. Prog Mater Sci 2006;51:427.

[50] Zhu YT, Huang JY, Gubicza J, Ungar T, Ma E, Valiev RZ. J Mater Res 2003;18:1908.

[51] Tian X, Woo C. Mater Sci Eng A 2004;369:210.

[52] Liu X, Golubov SI, Woo CH, Huang H. Mater Sci Eng A 2004;365:96. 